\title{
Régimen de insolvencia empresarial: Propuesta de unificación de los privilegios concursales para los países miembros de la comunidad andina de naciones. Estado del arte*
}

\author{
Sandra Julieta Fonseca López** \\ Candidata a Magister en Derecho \\ Universidad Sergio Arboleda
}

\begin{abstract}
Resumen
En el contexto mundial actual de globalización y apertura de fronteras, los negocios y las economías transfronterizas representan un sector en rápida evolución y las transacciones comerciales adquieren un mayor dinamismo impulsadas fundamentalmente por la estructura jurídica de la sociedades que cada día dan origen a operaciones jurídicas mas complejas. Esta realidad impone nuevos retos a las legislaciones nacionales que no se encuentran preparadas para enfrentar las exigencias del tráfico mercantil moderno. En áreas de cooperación o en proceso de futura integración, juega un papel muy importante el tema de la armonización y unificación del derecho concursal, por lo que los países deberán adoptar regímenes armónicos, modernos y eficientes que garanticen a sociedades, empresarios e inversionistas, tener certeza sobre la legislación a la que se acogen dentro del desarrollo de sus negocios.
\end{abstract}

\section{Palabras clave}

Armonización, Unificación, privilegios concursales, insolvencia empresarial, clases de créditos, sociedades transnacionales, acreedores y deudores extranjeros, cooperación jurisdiccional internacional, integración y cooperación interestatal, globalización, economía internacional, Comunidad Andina de Naciones.

\begin{abstract}
The current context of world's globalization, opening of borders, business and across-the-border economies in quick evolution, where the commercial transactions acquire a bigger dynamism pushed

Fecha de recepción del artículo: 1 de diciembre de 2007

Fecha de aceptación del artículo: 27 de diciembre de 2007

* Este artículo es resultado del proyecto de investigación titulado "Régimen de Insolvencia Empresarial: Propuesta de Unificación de los Privilegios Concursales para los Países Miembros de la Comunidad Andina de Naciones". Proyecto avalado por la Maestría en Derecho de la Universidad Sergio Arboleda y dirigido por el doctor LEONARDO ESPINOSA - Director Grupo Globalización y Derecho - Categoría B Colciencias.

** Abogada de la Universidad Pedagógica y Tecnológica de Colombia. Especialista en Investigación y Docencia con énfasis en ciencias jurídicas de la Universidad Sergio Arboleda. Candidata a Magíster en Derecho con énfasis en Derecho Mercantil Internacional de la Universidad Sergio Arboleda. Actualmente docente e investigadora de la Universidad Pedagógica y Tecnológica de Colombia, Tunja (Boyacá).
\end{abstract}


primarily by the artificial structure of the societies that day by day give origin to more complex legal operations; imposes new challenges to the national legislations that are not prepared to face the demands of the modern trade flows. In cooperation areas or in future integration processes, harmonization and legislative unification regarding Bankruptcy law play a critical role. This requires the countries' internal legislations to adopt harmonic, modern and efficient regimes that guarantee societies, managers and investors, legal security about the development of their business or in case of financial difficulties.

\section{key words}

Harmonization, Unification, privileges compete them, managerial insolvency, classes of credits, transnational societies, creditors and foreign debtors, jurisdictional international cooperation, integration and interstate cooperation, globalization, international economy, Andean Community of Nations.

\section{Problema y metodología del proyecto de investigación}

El artículo forma parte del proyecto de investigación titulado Régimen de Insolvencia Empresarial: Propuesta de Unificación de los Privilegios Concursales para los Países Miembros de la Comunidad Andina de Naciones y corresponde al estado del arte de la investigación. El objetivo del proyecto es elaborar una propuesta de unificación en materia de privilegios concursales, dentro de los procesos de insolvencia empresarial transfronteriza para los países miembros de la CAN, pero el problema especifico en el que se centrará el proceso de investigación es abordar la viabilidad para la elaboración de la propuesta.

Atendiendo a la clasificación tradicional acerca de metodologías y tipos de investigación, la estrategia metodológica aplicada al presente estudio tuvo en cuenta la naturaleza socio jurídica y normativa del problema objeto de estudio, por lo cual, se plantea un método de investigación aplicada - socio jurídica que permite relacionar el derecho con otras disciplinas del conocimiento y con fenómenos sociales, económicos, políticos, etc. Teniendo en cuenta las características propias del tema planteado, se enmarcará dentro del tipo de investigación explicativo, por cuanto está dirigida a analizar eventos sociales y económicos y su incidencia dentro de la estructura normativa nacional e internacional. A su vez relaciona dos variables, los privilegios concursales en los países miembros de la Comunidad Andina de Naciones, frente a las tendencias en la Unión Europea, todo ello en términos de armonización y unificación normativa.

\section{Introducción}

La transformación de mercados y sociedades nacionales, en mercados comunes y sociedades con sedes, sucursales y filiales en varios países del mundo - fenómeno que se presenta cada día con mayor frecuencia y dinamismo - ha generado que se supriman las fronteras Estatales para dar paso a la libre circulación de personas, capitales, bienes y servicios. Esta situación afecta factores fundamentales como la soberanía estatal (en otra época inmodificable), la condición de los extranjeros, el régimen jurídico de comerciantes y sociedades, la insolvencia empresarial transnacional y los privilegios concursales en situaciones de crisis de las empresas.

Vale la pena aclarar que el Derecho Concursal Internacional, en adelante D.C.I., es el sector del derecho internacional privado comercial, dedicado a regular y darle solución a los problemas planteados por el fenómeno de la insolvencia internacional. A su turno, la insolvencia internacional implica una situación de crisis del comerciante que se refleja en las dificultades por la que atraviesa la empresa que no puede afrontar debidamente el cumplimiento de las obligaciones contraídas. 
En áreas de cooperación y en proceso de futura integración, caso América Latina, o en áreas ya integradas caso Unión Europea, la actividad desarrollada por los agentes económicos, puede provocar situaciones de crisis de las empresas que tengan sedes en diversos países y esas son las denominadas precisamente insolvencias transfronterizas, que se presentan ante la imposibilidad de atender las obligaciones contraídas por el deudor con sus acreedores. Es en este aspecto donde juega un papel de vital importancia el tema de los privilegios concursales pues, a través de éstos, se verifica el cumplimiento de las obligaciones con los acreedores, el orden en el cual serán atendidos sus créditos y en qué proporción serán satisfechas las obligaciones contraídas por el deudor insolvente.

Un contexto mundial como el actual, aumenta las posibilidades y el riesgo de crisis de los diversos agentes económicos; razón por la cual se plantea a través de este proyecto la necesidad de armonizar $\mathrm{y}$ unificar las legislaciones en una materia de tan especial naturaleza como los privilegios concursales en procesos de insolvencia transfronteriza para los países miembros de la CAN.

La insolvencia internacional no solo afecta el buen funcionamiento de los flujos del mercado en el bloque económico involucrado. Además produce efectos en el buen funcionamiento del mercado global. Por ello, es necesario y pertinente que se adopten y apliquen medidas efectivas de cooperación y coordinación entre los Estados respecto del activo del deudor insolvente, sus obligaciones en favor de acreedores y especialmente sobre el tema de los órdenes y privilegios en materia concursal.

Lo anterior justifica la inminente urgencia de un estudio serio, que a partir de la experiencia de la Unión Europea permita abordar con profundidad la normatividad vigente en materia de insolvencia empresarial internacional en los países miembros de la CAN. La puesta en marcha de una propuesta seria de armonización y unificación legislativa debe analizar los aspectos similares y yuxtapuestos de las legislaciones vigentes en los países miembros. Así como impone el estudio de los excesivos privilegios de los que gozan hoy en día Entidades Estatales en el tema de hacienda pública e impuestos, resultado de modelos legislativos anacrónicos, establecidos aún en la actualidad por muchas legislaciones en América Latina y en el mundo.

La instalación de un sistema de Derecho Concursal unificado, traerá indudablemente como consecuencia el acrecentamiento de los intercambios comerciales, una mayor seguridad jurídica en el tráfico mercantil y un significativo aumento en la eficiencia de los procedimientos judiciales, lo cual resultará beneficioso para empresarios, sociedades e inversionistas locales y extranjeros.

\section{Unificación legislativa en materia de privilegios concursales}

Al abordar el tema de una posible armonización y / o unificación de los privilegios concursales dentro del marco de los procesos de cooperación e integración regional que se están adelantando hoy en día en el mundo y en el caso concreto de América Latina, se hace necesario acudir a la legislación vigente sobre insolvencia empresarial transfronteriza en los países miembros de la CAN y por supuesto al papel relevante que cumple el Derecho Internacional Privado en dicho proceso de integración jurídica.

El estudio sobre el tema de la armonización y unificación de los privilegios concursales para los países miembros de la CAN, debe abordarse desde de la experiencia Europea que es conside-rada como el más avanzado modelo, por su trayectoria, en materia de armonización y unifica-ción legislativa. Esa trayectoria y experiencia en el tema del desarrollo y evolución del derecho comunitario, convierte al modelo Europeo en la fuente más importante a partir de la cual puede aproximarse la construcción de un proyecto de integración y de derecho común en América Latina, este presupuesto, evidencia la necesidad de acudir a los sistemas actuales de insolvencia transfronteriza que tienen vigencia hoy en Europa. 
Tendencias actuales del Derecho Mercantil Internacional

El siglo XXI, se presenta como un entorno global en el cual se produce una marcada aceleración de los movimientos transfronterizos de personas, bienes, servicios, capitales e información. Dentro de este contexto propio de la hoy denominada comunidad global, se multiplican las necesidades por parte de los operadores comerciales y de las empresas, de relacionarse, adquirir bienes en el exterior, aunar esfuerzos y concretar negocios, ignorando de algún modo las fronteras interestatales (Feldestein 2000). Ese proceso ha generado que los actores del tráfico mercantil ajusten dentro del contexto de sus necesidades y al margen de los Estados, normativas supraestatales que se acomoden al ágil desarrollo y a la velocidad que exigen hoy en día los negocios transnacionales.

Dicha normatividad se ha desarrollado con el fin de propiciar a los empresarios, sociedades, comerciantes e inversionistas un clima de previsibilidad y seguridad jurídica internacional, lo que en últimas tiene como consecuencia una mayor posibilidad de desarrollo y prosperidad económica de los Estados.

Sara Feldstein (2003), afirma dentro de varios artículos científicos, publicados como resultado de sus procesos de investigación en temas de insolvencia empresarial transfronteriza, que en un contexto como el planteado con anterioridad, el Derecho Internacional Privado (D.I.P.), aparece como un instrumento insustituible en materia de integración jurídica, que como disciplina está llamada a contribuir como marco regulador e imperativo, en el logro de la armonización y unificación de las legislaciones de los países que conforman un esquema determinado de integración(Feldestein).

Así mismo, la autora considera, que un mercado común, como el que se pretende lograr a través de la CAN, requiere suprimir las fronteras para permitir la libre circulación de personas, capitales, bienes y servicios, lo cual afecta aspectos fundamentales de la soberanía estatal, entre los que se destacan: a) La condición de los extranjeros, b) El régimen jurídico de los comerciantes y las sociedades, y especialmente dentro de esta área, la regulación del fenómeno de la insolvencia y de la situación de crisis de las empresas (Feldestein 2000). Tema éste, que debe considerarse de fundamental importancia a la hora de emprender políticas de integración regional, teniendo en cuenta la relevancia que tiene para sociedades, empresarios e inversionistas de capital, tener certeza sobre la legislación a la que se acogen dentro del desarrollo de sus negocios.

El hecho de que los países integrados o en proceso de integración, tengan claridad acerca del tema de los privilegios concursales en materia de insolvencia empresarial, dentro de un contexto global como el actual, representa garantías, seguridad jurídica y previsibilidad para inversionistas nacionales y extranjeros.

Así pues, cuanto mayor sea el número de países de América Latina que en un bloque de cooperación o integración tengan legislaciones armónicas o uniformes, será mayor la viabilidad de abrir sus puertas a un prospero y promisorio desarrollo económico. Es precisamente en el desarrollo de este contexto económico mundial, en donde el D.I.P. se impone y adquiere importancia como aquel instrumento de Derecho interno que permite, a través de un marco jurídico imperativo, hacer viables los procesos de armonización y unificación de las legislaciones estatales, todo esto con miras a lograr una verdadera integración regional.

Importancia de la armonización y la unificación en materia de privilegios concursales para los países miembros de la CAN.

Luego de dar una mirada holística acerca del marco en el cual se desenvuelven hoy en día las transacciones mercantiles a nivel transnacional, de verificar la importancia que tiene para los países establecer alianzas transfronterizas y en 
consecuencia la armonización y unificación de sus legislaciones y de haber establecido el papel que juega dentro de este proceso el D.I.P., surge la necesidad de realizar una aproximación respecto de los procesos de integración legislativa en materia de privilegios concursales en los casos de insolvencia empresarial transfronteriza para los países miembros de la CAN.

Los cambios experimentados por la economía internacional durante las últimas décadas han desencadenado una actividad empresarial que, de forma creciente, está diseñada en clave mundial, sobre la que han repercutido decisivamente las crisis económicas periódicas, favoreciendo directamente la aparición de situaciones de insolvencia internacionales o transfronterizas y la consecuente iniciación de procedimientos concursales internacionales (Fernández Rozas 2003 p. 273). El número de casos de insolvencia transfronteriza ha ido en aumento en todo el mundo y esta situación requiere procedimientos de insolvencia uniformes, cooperación judicial más allá de las fronteras y términos jurídicos transfronterizos que garanticen la eficiencia, eficacia y equidad de los mencionados procedimientos, esto a su vez favorece que las legislaciones se encuentren en equilibrio frente a la agilidad y dinamismo con la que en el contexto global actual está avanzando el tráfico mercantil. Pues como ya se indicó, ello traería como consecuencia una mayor seguridad jurídica en las transacciones mercantiles y una evidente reducción de las incertidumbres de los inversionistas, nacionales y extranjeros, frente al estado crítico que representan hoy en día las divergentes instituciones jurídicas de los países miembros de un bloque económico como la CAN.

Gonzalo Capriles (2006), afirma que los países miembros de la CAN son Estados que mantienen constantes relaciones comerciales y que se caracterizan por una identidad idiomática, histórica, cultural y geográfica entre otras; desafortunadamente, en temas de armonización y uniformidad jurídica, no se ha llegado a proyectos concretos que verifiquen una aproximación real hacia una integración regional. Especialmente en el ámbito de procesos de insolvencia empresarial transfronteriza se presentan serias diferencias legislativas interestatales, lo cual se traduce en la falta de claridad cuando se adelantan dichos procedimientos a nivel de sociedades que tienen sedes en varios de los países miembros.

La situación anterior, evidentemente perjudica el dinamismo que caracteriza al tráfico mercantil de las sociedades transfronterizas modernas, por lo cual se hace urgente además de necesario, superar las diferencias legislativas entre Colombia, Ecuador, Perú y Bolivia, para lograr una mayor seguridad jurídica y promover la inversión nacional y extranjera dentro de los diferentes Estados que constituyen el bloque de la CAN. Esto facilitará sin lugar a dudas la creación y desarrollo de empresas en los países miembros, dentro de un clima de previsibilidad, confianza y seguridad jurídica en los negocios adelantados con otros países pertenecientes a bloques integrados como la Comunidad Europea.

\section{Técnicas de armonización legislativa}

Existen dos instrumentos fundamentalmente importantes que permitirían a los empresarios tener una mayor confianza a nivel jurídico en la proyección y concreción de sus inversiones en el ámbito transnacional, esas técnicas son la armonización y la unificación en materia de legislación mercantil, esto significa el retorno a la verificación del D.M.I. en todos los ámbitos de su competencia, como un derecho común y universal.

Es importante señalar que si bien los términos "armonización" y "unificación", pueden ser empleados de forma indistinta, es necesario sin embargo, que ambos vocablos sean tratados de manera rigurosa y específica, dado que tienen un alcance y unos efectos diferentes. Una verdadera unificación podría implicar la adopción de un texto común, a tratados, convenciones internacionales, y en ocasiones hasta su aplicación directa por los tribunales locales o su revisión 
por un tribunal supranacional; a diferencia del término armonización que debe ser entendido de una manera mucho más flexible y como paso previo e inicial para llegar a una verdadera unificación legislativa en materia mercantil.

El concepto de armonización se presenta caracterizado por su mayor flexibilidad y no necesariamente por implicar la adopción de un texto uniforme, ya que se refiere, mas bien a una simple aproximación de criterios jurídicos apoyándose en bases, leyes modelo, o doctrina común, que pueden servir de punto de partida para que los legisladores y jueces nacionales puedan coordinar el enfoque jurídico de un conflicto de intereses determinado (Garro 1992 p.p 114-117). La verdadera unificación implica no solo la coincidencia de reglas aplicables a una situación determinada, sino la identidad total del régimen jurídico entre países, la uniformidad legislativa, es quizás entonces, la técnica de mayor intensidad, profundidad y perfección, pero también la más difícil de lograr; no obstante, cada día resulta más frecuente alcanzar la uniformidad legislativa, sobre todo por vía convencional en áreas específicas del D.I.P., especialmente del Derecho Comercial Internacional, que es el área en la que más exitosamente se ha empleado este mecanismo (Feldestein 2000).

Tratándose de procesos de integración jurídica, hay escalas y grados que van desde la coordinación, la aproximación, la cooperación y la armonización hasta lograr una verdadera uniformidad jurídica. En este orden de ideas, la armonización legislativa, constituye uno de los mecanismos y herramientas indispensables para lograr seguridad y confianza en el tráfico mercantil internacional actual. Un proceso de integración sólido y eficaz solamente puede ser operativo en la medida en que los marcos jurídicos sean adecuados y ello se logra únicamente mediante el instrumento de la armonización legislativa (Basz 2000).

Como afirma Carlos J. Sarmiento Sosa (2006), la tendencia mundial de los grupos y las personas de relacionarse directamente a través de las fronteras sin la intervención del Estado (Annan 2001), fenómeno que se conoce como globalización económica, o sea, la convergencia de procesos económicos, financieros, comunicacionales y migratorios que genera interdependencia entre sectores de varias sociedades y concibe nuevos flujos y estructuras de interconexión supranacional (Luppino 2002), solamente se completará cuando haya una armonización de las normas jurídicas que permitan y faciliten integrarse a una economía cada día más interdependiente sin renunciar al derecho y al deber de verificar en cada caso la compatibilidad entre las normas a ser adoptadas y los intereses de los países, mediante un análisis serio y detenido de los textos jurídicos propuestos como base de armonización y unificación y de una apreciación analítica de los intereses que intentan proteger y las alternativas viables en cada caso particular (Garro 1992).

\section{Actores e instrumentos del derecho mercantil internacional}

La potestad de dictar leyes se ha considerado por mucho tiempo un atributo central de la soberanía estatal. El Estado ha sido entendido como la única instancia competente en la producción de derecho, tanto dentro del territorio nacional cono a nivel de las relaciones interestatales. Sin embargo la complejidad y la interdependencia de la sociedad moderna afectan este monopolio autoproclamado e impulsa la formación de un derecho más allá de la producción legislativa del Estado - Nación. Las condiciones de globalización del siglo XX han llevado a la formación de una sociedad mundial, que opera y se fundamenta sobre la base de distintos ámbitos sociales (economía, política, comercio, entre otros), cada uno de los cuales atiende a una función social específica (Mereminskaya, Mascareño 2005 p.p 1 y s.s.).

La producción este derecho anacional se efectúa en las zonas de contacto entre el derecho y otros sistemas sociales (Teubner, Gunther, 
1996). La creciente relevancia de la economía, la ciencia y la tecnología desplazan al Estado en su rol de liderazgo en la determinación de los lineamientos del sistema jurídico y le imponen el desafío de incorporar en su estructura normativa los mecanismos que le permitan reaccionar más eficientemente ante las expectativas creadas en otras esferas (Rogowski, 2005 p.p 4 y 14). Pues el contacto con la praxis económica de las transacciones internacionales modernas aporta una alta variabilidad de posibilidades para la producción de decisiones con consecuencias jurídicas. El resultado de esto ha sido denominado lex mercatorial $^{l}$ (Teubner, Gunter, 1996 p.p. 3-35).

Es en el contexto mundial actual descrito, donde surgen al margen de los Estados, entidades internacionales no gubernamentales ${ }^{2}$, como la Cámara de Comercio Internacional (C.C.I.), UNCITRAL, UNIDROIT, CNUDMI, quienes trabajan en la elaboración de leyes modelo, contratos tipo, o textos internacionales sobre arbitraje, usos y prácticas comerciales en todos los ámbitos que requieren las necesidades de los procesos mercantiles internacionales modernos. Pero sus contribuciones no se limitan a la mera producción por escrito de la realidad comercial, mas bien, su labor se orienta a la búsqueda de la "mejor solución", es decir, a la solución que más se adecue a las necesidades del tráfico comercial internacional, lo cual inevitablemente se traduce en la formulación de nuevas soluciones jurídicas (Herber, 2003 p.p 1-52).

Son varias las instituciones internacionales de este tipo, unas de carácter gremial, y otras intergubernamental, que han sido creadas, con el objetivo de promover y contribuir con la unificación de las reglas aplicables a los contratos y las negociaciones transnacionales (Oviedo Albán 2007). Igualmente puede hablarse de una serie de actores no estatales, como son las empresas multinacionales (Galgano, Marrellla, 2004 p. 17s.s.), que conforman el grupo de entidades supranacionales al margen de los Estados que hacen compilaciones en diferentes guías, normativas, leyes modelo, contratos y cláusulas tipo, aportando soluciones prácticas y eficientes a las necesidades que requieren en la actualidad los diferentes actores del tráfico mercantil, en el ejercicio de sus negocios ${ }^{3}$.

\section{Tendencia Europea sobre la unificación del derecho privado}

Para Elina Meremínskaya (2007), en la Unión Europea (U.E.), que representa el espacio físico de integración más avanzado en la actualidad, el tema de la unificación del derecho es tratado con viva intensidad, pues la opinión doctrinal Europea en su mayoría encuentra en el derecho uniforme un ideal, en tanto que constituye la respuesta más adecuada a los desafíos que imponen hoy en día los procesos de integración ${ }^{4}$. Los protagonistas de la integración se enfrentan en un punto clave (Galgano 2005): debe hacerse la unificación "desde arriba", mediante una codificación europea o "desde abajo" por la vías de la llamada lex mercatoria (Mereminskaya 2007).

Partiendo de la idea de que los ordenamientos jurídicos europeos tienen un núcleo común y se sostienen por valores compartidos ${ }^{5}$ numerosas voces académicas estiman estos presupuestos, como promisorios para poder llegar a una codificación Europea. Las investigaciones comparadas (Zimmermann, Whittaker, 2000) muestran que los jueces de los diferentes países de Europa, a pesar de usar técnicas jurídicas diferentes, llegan en muchos casos a soluciones concordantes al resolver cuestiones legales ${ }^{6}$.

Este hecho se debe a las raíces comunes de los ordenamientos jurídicos Europeos que se basan en el Derecho Romano, así como igualmente influyen en este fenómeno, las circunstancias políticas, sociales y económicas semejantes que se han dado a lo largo de la historia dentro de su territorio (Lando 2003).

En este punto vale la pena resaltar lo que con razón afirma Leonardo Espinosa en su artículo "Hacia un sistema contractual uniforme: modelos comparados", cuando hace especial 
énfasis en que si se pretenden estudiar los presupuestos e instrumentos sobre los cuales es viable la elaboración de un derecho privado armónico uniforme, se hace obligada una mirada al tronco común del Derecho Romano ${ }^{7}$ para que haga las veces de punto de encuentro (como presupuesto de la unificación) y de instrumento en el proceso unificador (Espinosa 2004).

\section{Situación actual de los procesos de insolvencia transfronteriza en la Unión Europea}

Afirma Fernández Rozas, que los cambios experimentados por la economía internacional durante las últimas décadas han desencadenado una actividad empresarial que, de forma creciente está siendo diseñada para transacciones en el ámbito de lo que hoy por hoy se denomina la comunidad global, sobre la cual han repercutido decisivamente las crisis económicas periódicas, favoreciendo directamente la aparición de situaciones de insolvencia internacionales o transfronterizas y la consecuente iniciación de procedimientos concursales internacionales (Fernández Rozas 2003).

El número de casos de insolvencia transfronteriza se ha incrementado en todo el mundo, obligando a las jurisdicciones nacionales a intervenir cada vez con mayor frecuencia en procedimientos de insolvencia con elementos transfronterizos y propiciando la necesidad de fomentar la comunicación y la cooperación judicial mas allá de las fronteras, con el fin de mejorar de modo general la eficiencia, eficacia y equidad de los mencionados procedimientos.

En Europa, la mayor dificultad se presentaba en torno a la territorialidad de la insolvencia, pues mientras ciertos Estados reconocían los efectos mundiales de un mandamiento de insolvencia, otros se mantenían reacios a hacer efectivo un mandamiento extranjero de aislar los bienes locales y minimizar la repercusión de los procedimientos extranjeros, con la consiguiente disminución de la confianza de los inversionistas. Dicha circunstancia, sin duda a traído como resultado el interés por una regulación adecuada de los procedimientos concursales internacionales.

De hecho, hasta bien entrada la década de los noventa, no existía ningún convenio internacional multilateral en la materia; en los últimos años esta situación parece que está variando $\mathrm{y}$, junto a la elaboración de ciertos convenios internacionales sobre procedimientos concursales internacionales, algunos países han incorporado normas especiales en materia de procedimientos concursales internacionales. Uno de los principales resultados de la Uncitral con ocasión de su XXV período de Sesiones del Plenario de la Comisión, fue la consecución de la Ley Modelo de la Uncitral sobre la insolvencia Transfronteriza ${ }^{8}$, aprobada en 1997 y modificada en 2003, cuya finalidad es promover la adopción de una normativa legal moderna y equitativa para aquellos casos en que un deudor insolvente tenga bienes en más de un Estado.

El texto trata de las condiciones en las cuales la persona que administra un procedimiento de insolvencia extranjero tiene acceso a los tribunales del Estado que adoptan la Ley modelo; determina las condiciones del reconocimiento de un proceso extranjero de insolvencia e indica las medidas de protección a favor del administrador extranjero, permitiendo a los tribunales y administradores judiciales de distintos países cooperar mas eficazmente, así como también enuncia las disposiciones sobre la coordinación de los procedimientos de insolvencia que tienen lugar conjuntamente en Estados diferentes. Pretende ser una ayuda para que los Estados puedan dotar a su Derecho de insolvencia con una normativa moderna, equitativa y armonizada, para resolver con mayor eficacia, los supuestos de insolvencia internacional, es decir, casos en los que el deudor tiene bienes en mas de un Estado o en los que concurren acreedores locales y / o extranjeros (Fernández Rozas 2003).

Esta normativa que es pionera y modelo en el tratamiento de los procesos de insolvencia transfronteriza, recoge además las prácticas mas 
eficientes y actualizadas de la administración de insolvencias internacionales, respeta las diferencias que se dan entre los derechos internacionales internos, no intenta modificar el derecho sustantivo y presenta soluciones significativas. Su objetivo es aportar una serie de instrumentos que proporcionen un sistema de insolvencia eficaz, equilibrado y eficiente que indague las posibles vías de reestructuración judicial del deudor. $^{9}$

Como señala Fernández Rozas, en el mercado único se presenta como un sector esencial el relativo a los institutos concursales por incidir el derecho concursal de manera directa en los mecanismos de estabilidad del mercado. Sin embargo hasta los últimos tiempos este sector se había presentado como uno de los reticentes a la armonización y ello por dos razones: la cualidad de los procedimientos concursales como procedimientos universales y, en íntima relación, la particular sensibilidad de esta materia en el marco de las relaciones Estado - Sociedad Economía-Derecho. Evidentemente, el carácter de procedimiento universal de los procedimientos concursales que afectan a todo el patrimonio y todos los acreedores del deudor, supone un obstáculo para la armonización, sobretodo cuando el deudor posee bienes o tiene acreedores en diferentes Estados (Fernández Rozas 2003 p. 407 s.s).

El Convenio de 1995 intentaba solventar el contrasentido que suponía que la actividad de las empresas dependiese cada vez más de normas de Derecho comunitario, y que, sin embargo la liquidación de las mismas, se regulase exclusivamente por la normatividad de origen nacional; por eso este instrumento tuvo la pretensión de simplificar las formalidades a que estaban sometidas el reconocimiento y ejecución recíprocas de las resoluciones judiciales en un afán de reforzar la protección jurídica de los operadores jurídicos establecidos dentro de la comunidad. Sin embargo la incorporación de los Estados miembros a este instrumento no se produjo, toda vez que el Reino Unido se opuso de manera tajante (Balz 1996 p.485 s.s). En todo caso ese texto consistía mas bien en una mera declaración de principios con el fin de facilitar su acogida en los ordenamientos nacionales.

El reglamento (CE) 1346/00 del Consejo, del 29 de mayo de $2000^{10}$, sobre procedimiento de insolvencia a supuesto un importante avance, superando muchos de los obstáculos en presencia al dar soluciones concretas a la cooperación judicial en supuestos de insolvencia transfronteriza, con el consiguiente reconocimiento de decisiones y normas uniformes de conflicto sobre Ley aplicable. Este reglamento se enmarca en el ámbito de la regulación internacional de la insolvencia de carácter transfronterizo (quiebra internacional), que desde los últimos años ha constituido preocupación prioritaria del legislador. No hay que olvidar que las crisis económicas generalizadas y periódicas desde los años setenta, así como la progresiva globalización de la economía internacional, han impulsado, entre otros factores, la búsqueda de un régimen uniforme regulador de la quiebra internacional (Fernández Rozas 2003 p. 408). De otro lado, el Reglamento (CE) 1346/00 del Consejo tiene por objeto los procedimientos transfronterizos de insolvencia dadas las crecientes repercusiones transfronterizas de las actividades empresariales, así como la incidencia que dichas empresas tienen en el mercado interior.

Por todo ello, forman parte del contenido del reglamento, disposiciones que regulan la competencia para la declaración de procedimientos de insolvencia, así como disposiciones relativas al reconocimiento de esas decisiones, la participación de los acreedores y la situación de los trabajadores, así como normas de competencia y Derecho aplicable. Pese a que aún en Europa se está apenas fortaleciendo la posibilidad de unificación o armonización del régimen jurídico de los instrumentos concursales, el Reglamento (CE) 1346/ 00 representa un instrumento muy valioso para iniciar el camino hacia esa armonización, pues en él se da respuesta a algunos problemas planteados por la participación de los acreedores en los procedimientos de insolvencia transfronteriza, 
particularmente los relativos a la cooperación judicial civil, que representa cuestión previa a partir de la cual se deben abordar otros aspectos del derecho sustantivo o material (Virgos; Garcimartín 2002 p.67-100).

\section{Derecho y privilegios concursales}

Los procedimientos concursales en el mundo tienen una serie de características y principios que fundamentan su naturaleza y que deben ser tenidos en cuenta a la hora de iniciarse una actuación procesal de este tipo. En este orden de ideas vale la pena citar las características generales que rigen estos procedimientos, que son entre otras, la Universalidad, la territorialidad y la generalidad; presupuestos que reflejan la naturaleza del concurso de acreedores como un procedimiento de ejecución colectiva en el que el conjunto del patrimonio del deudor y todos los créditos constituidos contra éste son enfrentados en un único procedimiento que pretende la ordenada liquidación de dicho patrimonio o su saneamiento (Arenas García 2007).

La característica de la universalidad se refiere a que el procedimiento abierto en un Estado abarcará, en lo que se refiere a la masa activa del concurso, el conjunto de patrimonio del deudor, incluso aunque esté situado fuera del Estado de apertura del procedimiento, $\mathrm{y}$, por lo que respecta a la masa pasiva, al conjunto de acreedores del concursado, con independencia de donde se encuentren y de donde se haya constituido el crédito que reclaman. Frente a este planteamiento se opone la territorialidad del procedimiento que mantiene que el procedimiento concursal abierto en un determinado Estado solamente puede afectar a los bienes situados en dicho Estado (Fernández, Arenas, Asensio 2007).

Dicho lo anterior solamente resta hablar del principio de la generalidad que se refiere a la circunstancia de que el inicio del procedimiento tiene como consecuencia la transformación de un conjunto de relaciones bilaterales entre el deudor concursado y sus acreedores en una situación colectiva en la que una pluralidad de acreedores tienen derechos sobre el mismo conjunto de bienes, en consecuencia el derecho de cada uno de los acreedores se ve condicionado y limitado por los derechos de los demás acreedores y por el régimen del concurso ${ }^{11}$.

En materia de privilegios concursales en Europa vale la pena destacar a uno de los mejores y mas importantes exponentes y tratadistas sobre el tema, Veiga Copo (2004), en su libro "los privilegios concursales", afirma, y con toda razón, que la clave de un correcto sistema concursal, debe producir como efecto, tanto una mayor prontitud en el tratamiento de las insolvencias materiales que pueden ser encausadas por soluciones económicas viables, saneamiento, ayudando a que acreedores y deudores cooperen ante el problema de la insolvencia (lo cual en ocasiones es imposible), como a una rápida, efectiva y justa, en la medida de lo posible, liquidación, del patrimonio del concursado ${ }^{12}$ que garantice el pago de la mayor parte de acreencias de manera equitativa.

El privilegio tiene su razón de ser y aunque ésta no sea homogénea para la enorme tipología de los mismos, su causa y justificación funcional, es que constituye la herramienta o instrumento que permite la tutela del crédito, una tutela conflictual que permite discriminar y jerarquizar e incluso degradar a los acreedores concurrentes en un patrimonio deficitario $\mathrm{y}$, que, al mismo tiempo, permite reducir los costes de las transacciones en la contratación de garantías dentro de lo que es una mayor o menor aversión al riesgo. Ahora bien el abuso de esos privilegios, es lo que genera disfuncionalidades en pro de consecuentes desnaturalizaciones importantes (Veiga 2004).

El privilegio por si mismo no genera violación del principio de la paridad, ni tampoco conduce al ostracismo del crédito ordinario pero su utilización desmesurada y egoísta sí, por esta razón, la clave de un sistema concursal más correcto pasa por una drástica reducción y a la vez racionalización de los privilegios ${ }^{13}$. La preferencia 
creditual, es una generalización del principio de responsabilidad patrimonial universal que opera precisamente cuando actúa o es exigible dicha responsabilidad. No se busca tanto proteger al acreedor o acreedores del comportamiento del deudor, como tratar de inmunizar a algunos acreedores de la concurrencia y de las pretensiones legítimas de otros.

El crédito privilegiado significa, en primer lugar crédito preferente, y como toda preferencia tendrá una fundamental razón de ser en un marco de concurrencia, en este caso, con otros acreedores. Si un acreedor puede garantizar la financiación que concede constituyendo una garantía real sobre un bien del deudor que le permita una satisfacción prioritaria, entonces no cabe duda que es más eficiente que el principio de la par condicio creditorum. Sin duda, hoy en día esta regla tiene mas de mito que de realidad (Veiga 2004).

Este punto de vista doctrinal respecto de los privilegios concursales, constituye sin duda alguna un reflejo claro de la realidad acerca de los criterios con que se manejan hoy por hoy los procedimientos concursales no solo en Europa sino en el mundo. Esto convierte el principio fundamental de la par conditio creditorum, en una falacia para aquellos acreedores que no tienen ningún tipo de privilegio para garantizar el pago de sus créditos, haciendo del proceso concursal la forma mas "legal", de ver desaparecer la posibilidad de hacer exigibles sus créditos, dentro de la maraña de acreedores con privilegios exorbitantes.

Acogiendo la teoría del Doctor Veiga Copo, es imperiosa la necesidad de que en los países miembros de la C.A.N, en donde los procesos concursales trasnacionales reflejan claramente gran disparidad de normas en este sentido, adopten medidas urgentes, ajustando, reformando $\mathrm{y}$ armonizando sus legislaciones en lo que respecta al tema de los privilegios concursales en procesos de insolvencia transfronteriza. Este trabajo debe ser cristalizado bajo los principios de universalidad y generalidad que fundamentan la naturaleza internacional de los mencionados procedimientos.
El primer paso hacia el logro de dichos objetivos exige que los bloques integrados como la C.A.N., trabajen de manera coordinada en la unificación de las disposiciones respecto del orden de asistencia de los acreedores dentro de un proceso de insolvencia, para que se trate de procesos justos y equitativos en donde se permita a los acreedores participar de manera equilibrada e igualitaria en el proceso de liquidación o reestructuración de un determinado patrimonio, con el fin de recuperar sus créditos o por lo menos parte de ellos; así como también deben examinarse de manera exhaustiva, los privilegios exhorbitantes con que cuenta hoy en día la Hacienda Pública en muchos de los ordena-mientos jurídicos vigentes.

Siendo las economías de los países miembros de la C.A.N., economías similares, en vía de desarrollo y que adelantan procesos de cooperación tendientes a una posterior integración, es fundamental que se promueva seguridad jurídica para los actores del tráfico mercantil internacional en este sentido.

Trayectoria del sistema de fuentes internacionales en América Latina en materia de insolvencia transfronteriza y la Ley modelo de la CNUDMI 14 (UNICTRAL).

Adolfo A.N. Rouillon (2000), en su artículo "Concursos con repercusión trasnacional y Ley Modelo de la CNUDMI (UNCITRAL) sobre insolvencia transfronteriza", hace un análisis sobre la trayectoria del tema de la insolvencia transfronteriza para algunos países de Sur América, estableciendo que al inicio del siglo XXI, en los países Latinoamericanos, el panorama que exhibe el régimen concursal, en materia de insolvencias transfronterizas está caracterizado por la insuficiencia y la falta de actualización en sus reglas, tanto en las de fuente internacional como las de fuente interna.

Respecto de las fuentes de carácter internacional que tienen relevancia para el caso concreto que ocupa la atención de este estudio, en varios países de América Latina, dichas fuentes continúan 
siendo solamente las contenidas en el tratado de Montevideo de 1889 (ratificado por Perú, Bolivia, Colombia, Paraguay, Uruguay y Argentina) y en el Tratado de Montevideo de 1940 (ratificado por Paraguay, Uruguay y Argentina). En los pocos casos que se ha hecho aplicación de estos tratados, se ha puesto en evidencia que sus reglas no conducen a soluciones rápidas, prácticas ni eficientes a los problemas que plantean cada vez con mayor frecuencia los concursos con repercusión transfronteriza (Rouillon 2000).

Dichos estudios, adelantados dentro de procesos de investigación (que se encuentran publicados en ANALES de la academia Nacional de Derecho y Ciencias sociales de Buenos Aires, (Año XLIII, segunda época, número 37)), concluyen que luego de efectuar seguimientos concretos a procesos de insolvencia transfronteriza, se evidencia que esos tratados que son fuente única para muchos países de Sur América, en materia derecho de insolvencia transfronteriza, no cumplen con las expectativas ni solucionan de manera eficiente los problemas que con mayor frecuencia presentan los procedimientos concursales transfronterizos.

Además, con esta investigación se pone de manifiesto que algunos de los países que han firmado estos tratados, durante los últimos diez años han incrementado sus relaciones económicas y el intercambio comercial, con países como Brasil y Chile, dos naciones que no son parte de esos tratados ni han manifestado su intención de adherirse a ellos.

La exposición del académico citado, permite verificar la escasa relevancia actual de los tratados de Montevideo, situación preocupante, ya que en muchos casos para los países miembros y no miembros de la C.A.N, éstos tratados constituyen el único régimen de fuente internacional en vigencia para insolvencias transfronterizas.

Esa pobreza normativa, frente a la realidad económica de los tiempos modernos, hace prever que los Jueces de los diferentes países miembros o no de la CAN, deberán enfrentar cada vez un número más alto de casos con cuestiones internacionales de insolvencia. A pesar de esto la realidad legislativa actual demuestra que el derecho de insolvencia transfronteriza en algunos países, carece de reglas modernas para solucionar los diferentes problemas que pudieran presentarse en la materia.

Lo anterior permite reafirmar la necesidad de una legislación armónica o unificada, acorde con las necesidades de los ágiles movimientos mercantiles, que permita el reconocimiento de los procedimientos extranjeros de insolvencia, el acceso a la justicia de los diferentes países miembros por parte de los administradores de esos procedimientos, así como la efectiva cooperación internacional entre los jueces que manejen los procedimientos concursales en los distintos estados.

\section{La ley modelo de la CNUDMI(UNCITRAL), sobre insolvencia transfronteriza ${ }^{15}$.}

El más ambicioso intento multinacional de convenio sobre procedimientos concursales llevado a cabo en los últimos tiempos, ha sido sin duda alguna, la Convención de la Unión Europea sobre procedimientos de insolvencia. Dentro de un ámbito favorable a la armonización legislativa como lo es el contexto de la Unión Europea que compone el espacio geográfico multinacional más fuertemente integrado en materia económica en el mundo, se ha trabajado con avances y retrocesos desde 1960 en diversos borradores de convenios en la materia.

Se estableció entonces, que la alternativa de mejorar la legislación interna de los países creando reglas de cooperación en los procedimientos de insolvencia con repercusión transfronteriza, era la adopción de un régimen moderno y eficiente, que contemplara los verdaderos intereses nacionales dentro de la esfera internacional (aumentando la previsibilidad y disminuyendo la tasa de riesgo de los países), y los de sus empresas en dificultades cuando ellas acuden 
a procedimientos de insolvencia buscando la reorganización, la preservación de valor y el mantenimiento de empleos; para lo cual es necesario introducir en las legislaciones internas reglas que posibiliten la cooperación internacional, el reconocimiento de los procesos concursales, y el acceso de los funcionarios y de los acreedores foráneos a estos últimos.

En este estado de las cosas y partiendo del análisis de la realidad y de la experiencia internacional en la materia, la Comisión de las Naciones Unidas para el Derecho Mercantil Internacional (CNUDMI), más conocida por su sigla UNCITRAL, ha elaborado una Ley modelo sobre la insolvencia transfronteriza, con una guía para su incorporación al derecho interno de los Estados.

La Ley Modelo, "recoge las prácticas, en materia de insolvencia internacional transfronteriza, que caracterizan a los sistemas más modernos y eficientes de administración de las insolvencias internacionales", a la vez que, "respeta las diferencias que se dan de un derecho interno procesal a otro y no intenta unificar el derecho sustantivo de la insolvencia, pero su régimen si ofrece soluciones que pueden ser útiles", a cualquier estado que "quiera dotar a su derecho de la insolvencia de una normativa moderna, equitativa y armonizada para resolver con mayor eficacia los casos de insolvencia transfronteriza"16.

Otra ventaja es su flexibilidad, inherente a toda Ley Modelo, que hace posible a cada Estado introducir modificaciones en el texto uniforme. Aunque claro está, no es deseable un número abundante de supresiones o modificaciones, ya que, el menor número de cambios es lo que permite alcanzar el mayor grado de armonización internacional.

A lo anterior se agrega el acento puesto en la cooperación internacional entre jueces y representantes de procedimientos concursales, sumado al claro estimulo de la comunicación directa entre ellos, lo cual permite la actuación rápida con miras a eliminar las "operaciones fraudulentas de deudores insolventes"17, que hoy, gracias a la interconexión mundial y a la facilidad de desplazamiento electrónico, de capitales, puede, velozmente ocultar o transferir activos a otras jurisdicciones. Los mecanismos de cooperación transfronteriza establecidos en la Ley Modelo tienen por finalidad evitar este fraude internacional ${ }^{18}$.

Todo ello contribuye a afianzar los valores de previsibilidad y seguridad jurídica, tan tenidos en cuenta a la hora de calificar el riesgo de un país. En palabras del Texto de la Ley modelo "La falta de previsibilidad sobre como se administrará una eventual insolvencia transfronteriza, obstaculiza el flujo de capitales y desincentiva la inversión transfronteriza"; mientras que, por el contrario, "todo dispositivo de derecho interno que permita coordinar la administración de insolvencias transfronterizas abre vías para adoptar soluciones sensatas que pueden interesar tanto a los acreedores como al deudor, por lo que la presencia de este tipo de mecanismos en el derecho interno de un Estado es percibida como un factor ventajoso para toda inversión u operación comercial en ese estado" (Ley Modelo de la CNUDMI sobre insolvencia transfronteriza Cap. IV No. 13).

El aumento de la previsibilidad en un área especialmente sensible y muy tenida en cuenta por el inversor extranjero, como es la existencia de reglas claras y no discriminatorias para tratar las relaciones entre acreedor y deudor en contextos de crisis o de insolvencia, constituye un factor que influye de manera directa en la disminución de la tasa de riesgo de un país.

En Colombia, el Nuevo régimen de insolvencia empresarial Ley 1116 de 2006 entró en vigencia el pasado 28 de Junio de 2007 e incorpora al ordenamiento jurídico Colombiano la Ley Modelo de la CNUDMI sobre insolvencia transfronteriza, de manera que Colombia queda automáticamente incluida en el conjunto de países de la comunidad internacional que ya acogieron 
en su derecho interno el modelo de la mencionada comisión, como es el caso de México dentro del ámbito Latinoamericano ${ }^{19}$.

La citada Ley Colombiana, reconoce la importancia de desarrollar un marco para la cooperación y la coordinación transfronteriza en casos de insolvencia, al hacer esto, Colombia se convierte en el décimo tercer país del mundo en promulgar una legislación que incorporó la Ley Modelo de la CNUDMI, sobre insolvencia transfronteriza, junto con Eritrea (1998), México (2000), Sur Africa (2000), Japón (2000), Montenegro (2002), Rumania (2003), Polonia (2003), Serbia (2004), Las Islas Vírgenes Británicas (2005), Los Estados Unidos de América (2005), Gran Bretaña (2006), y Nueva Zelanda (2006).

La adopción de la Ley Modelo es el primer paso en la promoción de una seria y eficaz cooperación y coordinación en casos de insolvencia transfronteriza. Para facilitar la implementación efectiva, los jueces colombianos, profesionales de insolvencia y abogados deben estar familiarizados no solo, con las disposiciones de la Ley 1116 en cuanto que se relacionan con insolvencia transfronteriza, sino también con la forma como dichas disposiciones deben aplicar en la práctica, para hacer efectiva y eficaz la implementación, de dichas disposiciones normativas a las regulaciones vigentes (Clift 2006).

\section{Conclusiones}

En materia de integración regional y jurídica el papel del Derecho Internacional Privado es de primordial importancia ya que se fundamenta como un instrumento insustituible que permite a partir del derecho interno, imperativo y Constitucional, la posibilidad de iniciar de políticas de integración regional, armonización y unificación legislativa.

Son dos los instrumentos o técnicas jurídicas que permitirían a los empresarios tener una mayor previsibilidad y seguridad jurídica para la proyección y concreción de sus inversiones en el ámbito transnacional: la armonización y la unificación de la legislación mercantil, esto significa para los países que están en proceso de integración el retorno a la verificación del D.M.I. en todos los ámbitos de su competencia, como un derecho universal o global.

La aplicación de algunos instrumentos internacionales existentes en la actualidad en materia de insolvencia empresarial transfronteriza en América Latina, tales como los Tratados internacionales, han puesto en evidencia que sus reglas no conducen a soluciones rápidas, prácticas ni eficientes a los problemas que plantean cada vez con mayor frecuencia, los concursos con repercusión transfronteriza.

En áreas o bloques de cooperación o en proceso de futura integración, juega un papel de vital importancia el tema de la armonización y unificación en materia de privilegios concursales, por lo que las legislaciones internas de los países deben adoptar regímenes armónicos, modernos $\mathrm{y}$ eficientes que garanticen a sociedades, empresarios e inversionistas, tener certeza sobre la legislación a la que se acogen dentro del desarrollo de sus negocios o en el caso de presentarse una situación de insolvencia empresarial.

El hecho de que los países integrados o en proceso de integración, tengan claridad acerca del tema de los privilegios concursales en materia de insolvencia empresarial; dentro de un contexto global como el actual, implica garantías, seguridad jurídica y previsibilidad para inversionistas nacionales y extranjeros. Cuanto mayor sea el número de países América Latina que, en un bloque de cooperación o de integración tengan legislaciones armónicas o uniformes, se abrirán con mayores posibilidades las puertas a un rápido y prospero desarrollo económico.

Es necesario superar las diferencias legislativas en materia de insolvencia empresarial y especialmente en el tema de privilegios concursales entre Colombia, Ecuador, Perú y Bolivia, con miras a 
lograr una mayor previsibilidad, confianza y seguridad jurídica y por consiguiente obtener el acrecentamiento de la inversión nacional y extranjera dentro de los diferentes Estados miembros de la CAN.

La integración y la uniformidad legislativa, son fenómenos que si bien encuentran sus antecedentes en civilizaciones muy antiguas como la Romana, representan el antecedente mas claro del derecho comunitario. Se manifiestan con toda su fuerza a partir de la segunda mitad del siglo XX y en la actualidad se presentan como alternativas prácticamente insustituibles para que los Estados puedan insertarse a la denominada aldea global.

Es realmente muy poco lo que se ha escrito respecto del tema concreto de armonización y unificación de los llamados "privilegios concursales", mientras que se encuentra abundante bibliografía respecto de la necesidad de unificación de los procesos de insolvencia empresarial transfronteriza, no solo en Europa sino en América Latina. Esto abre las puertas para que se avance en nuevos trabajos y procesos de investigación respecto del tema concreto del orden de acreedores en procesos de insolvencia transfronteriza.

\section{Notas}

1 Véase sobre Lex Mercatoria Fernández Rosas, José C, Ius Mercatorum, Autorregulación y Unificación del Derecho de los negocios transnacionales, Madrid España, 2003.

${ }^{2}$ Consulte sobre las herramientas de unificación del Derecho, Mereminskaya, Elina, "Impactos de la integración económica en el Derecho Privado", Revista de Derecho, Universidad Austral de Chile, Vol. XV, 2003, p.p. 59-73.

3 Ampliación respecto de este tema, véase: ALBÁN OVIEDO, Jorge. "Actores e Instrumentos del Derecho Mercantil Internacional" Bogotá 2007.

${ }^{4}$ Contrario a esta posición es, por ejemplo, Legrand, P., "Against a European Civil Code",
Modern Law Review, 1997/60, p. 44; véase una detallada presentación de la discusión por Nottage, L., "Convergence, Divergence, and the Middle Way in Unifying or Harmonising Private Law", www.iue.it/LAW/res/nottage/EUI WorkingPaper4.pdf (mayo de 2003).

${ }^{5}$ Véase por ejemplo, Möllers, T., "The Role of Law in European Integration", The American Journal of Comparative Law, 2000/4, p. 688 y ss., quien invoca como tales valores los derechos fundamentales, economía social del mercado y políticas ambientales, el pasado y los intereses comunes de los países europeos.

${ }^{6}$ Véase la investigación del grupo The Common Core of European Private Law Project: Zimmermann, R./Whittaker, S., Good faith in European Contract Law, Cambridge, University Press, 2000, en particular p. 653. Los juristas de los catorce países europeos tenían que resolver por sus derechos nacionales treinta casos típicos. En once de los casos el resultado fue el mismo; en nueve fue el mismo excepto uno o dos países; en diez de los casos se mostraron divergencias notables, las cuales, sin embargo, no corresponden a la divergencia entre civil y common law.

${ }^{7}$ Ver sobre Derecho Concursal Romano Unificado: Zambrana Moral, Patricia "Derecho Concursal Histórico" Tomo I. Cap. I La insolvencia de los derechos en la antigüedad. Cap. II La cessio bonorum en el derecho concursal romano. Cap III. La cesio de bienes como figura concursal en el derecho común europeo.

${ }^{8}$ La Ley Modelo de Uncitral. Recopila los resultados de ejercicios anteriores en materia de procedimiento concursal internacional, toma en consideración los resultados de otros trabajos, entre ellos: el Convenio de la Unión Europea relativo al procedimiento de insolvencia (1995), el Convenio Europeo sobre ciertos aspectos internacionales de la quiebra (Convenio de Estambul de 1990), los Tratados de Derecho Internacional Privado de Montevideo de 1889 y 1940, la Conven-ción sobre la quiebra de los Estados 
Nórdicos (1933), la Convención de la Habana de 1928 (Código Bustamante), y también las consideraciones propuestas por organizaciones no gubernamentales, como la Model International Insolvency Cooperatión Act (MIICA) y el Cross Border Insolvency Concordat, creadas por el "Comité J" de la Sección del Derecho Empresarial de la Asociación Internacional de Abogados.

${ }^{9}$ LEY MODELO DE LA UNCITRAL sobre Insolvencia Transfronteriza y la guía para su incorporación por parte de los Estados. Texto completo en varios idiomas, incluido el castellano se encuentra en: http://www.uncitral.org/uncitral/ es/uncitral_texts/insolvency/1997Model.html

10 Texto completo del REGLAMENTO (C.E.) Número 1346 del 29 de Mayo de 2000 DEL CONSEJO EUROPEO, sobre Procedimientos de Insolvencia. Disponible en: http://eurlex.europa.eu/LexUriServ/site/es/oj/2000/1_160/ 1_16020000630es00010018.pdf

11 Véase sobre procedimientos concursales Fernández Rozas, José C; Arenas G, Rafael; De Miguel A, Pedro A. "Derecho de los negocios internacionales" Cap. 8 p.p. 561 y s.s.

12 Sobre esta reflexión, en profundidad SCHMIDT, ZGR (1986), p. 178 y ss., especialmente p. 181; también en SCHIMIDT, "Fundamentos del nuevo derecho concursal Alemán", Estudios sobre el anteproyecto de Ley concursal de 2001. (GARCIA VILLAVERDE / ALONSO UREBA/ PULGAR (Dirs.)), Madrid 2002 p. 22.

${ }^{13}$ Véase ampliación respecto del tema en VEIGA Copo, Abel B. "La delimitación de la masa pasiva en el concurso: del crédito privilegiado al subordinado."Madrid, España 2007 pág. 2 y s.s.

${ }^{14}$ La Comisión de las Naciones Unidas para el derecho mercantil internacional (CNUDMI) se creó con la finalidad de promover la armonización y unificación progresivas del derecho mercantil internacional. Específicamente a nivel de insolvencia transfronteriza véase La Ley Modelo de la CNUDMI sobre la insolvencia transfronteriza. Naciones Unidas. New York 1998

${ }^{15}$ Aprobada por la CNUDMI el 30 de mayo de 1997 y modificada en el año 2003. Esta Ley Modelo tiene por objeto ayudar a los Estados a dotarse de un régimen de la insolvencia moderno, armonizado y equitativo que permita resolver con mayor eficacia los casos de insolvencia transfronteriza, entre los que cabe señalar todo caso en el que el deudor insolvente tenga bienes en más de un Estado o en el que algunos de los acreedores del deudor no sean ciudadanos del Estado en donde se haya abierto el procedimiento de insolvencia. La Ley Modelo respeta las diferencias que se dan de un derecho procesal interno a otro y no intenta unificar el derecho sustantivo de la insolvencia, pero su régimen sí ofrece soluciones que pueden ser útiles por razones significativas, en aspectos como los siguientes: asistencia que se haya de recabar en el extranjero para un procedimiento de insolvencia abierto en el Estado promulgante; acceso del representante extranjero a los tribunales del Estado promulgante; reconocimiento de un procedimiento extranjero; cooperación transfronteriza y coordinación de procedimientos concurrentes". Nota tomada de: http://www.uncitral. org/uncitral/es/uncitral_texts/insolvency/ 1997Model.html

${ }^{16}$ Tomado de: Guía para la incorporación al derecho interno de la Ley Modelo de la CNUDMI sobre la Insolvencia Transfronteriza Cap. I Finalidad y Origen Numeral 2.

${ }^{17}$ Fraude a la Ley y Operaciones fraudulentas. Consultar en: Guía para la incorporación al derecho interno de la Ley Modelo de la CNUDMI sobre la Insolvencia Transfronteriza Cap. I Finalidad y Origen Numeral 14.

18 Véase sobre Fraude a la Ley: José Carlos Fernández Rozas y Sixto Sánchez Lorenzo "Derecho Internacional Privado". Segunda Edición Madrid España, 2001. p.p 210 y s.s. 

PARA LOS PAísES MIEMBRos DE LA COMUNIDAD ANDINA DE NACIONES. ESTADO DEL ARTE

${ }^{19}$ Nuevo régimen de insolvencia empresarial, Ley 1116 de 2006. Cartilla elaborada por el Ministerio de Comercio, industria y Turismo y la Superintendencia de Sociedades. Bogotá Julio 2007.

\section{Referencias}

Annan, K. (2001). Que Es la Globalización?, www.elcomercio.com.pe obtenido el día 14 de Junio de 2007 en www.analítica.com

Basz, V. A. XII (2002). Temas de Derecho Privado. Armonización legislativa en áreas integradas. Argentina, Departamento de Derecho Privado de la Facultad de Derecho de la Universidad de Buenos Aires.

Candelario, M. \& Rodríguez G.A.(1998, Septiembre). Derecho y lex La empresa en crisis Derecho actual. Ed. Cuidad de Argentina.

Capriles, G. A., II. (2006, Mayo). Fronteras e Integración. Ajustes en los países de la Comunidad Andina de Naciones para participar en los procesos de integración regional. Disponible en www.eclac.org/ ...paginas/2/22962/CAPRILES-AJUSTES $\%$ 20PAISES\%20COMUNIDAD\%20ANDINA \%20PARTICIPAR\%20PROCESOS.PDF

Clift, J. (2007). Senior Legal Officer. Documento emitido por la Secretaría de la CNUDMI, Oficina de Asuntos Legales de las Naciones Unidas, con ocasión de la adopción por parte del Gobierno Colombiano de la Ley Modelo de la CNUDMI Sobre Insolvencia Transfron-teriza, mediante la Ley 1116 del 27 de Diciembre de 2006.

Feldstein, de Cárdenas S. A. (2003, Enero). Síntesis Forense, El Derecho Internacional Privado y los procesos de integración regional". Colegio de Abogados de San Isidro Argentina.

Feldstein, de Cárdenas S.A. (2000, Abril). Revista Jurídica de San Isidro. La insolvencia
Internacional en la Argentina: harmonización legislativa a la europea?. Extraído 14 de Abril de 2007 de http://www.derecho org.com.es

Fernández Rozas, J.C. (2003). Ius Mercatorum, Autorregulación y Unificación del Derecho de los negocios transnacionales. Madrid España. p.p 273 y s.s. 407 y s.s.

Fernández Rozas, J.C. \& Sánchez Lorenzo, S. (2001). Derecho Internacional Privado". Madrid España, Segunda Edición.

Fernández Rozas, J.C; Arenas García, R. \& De Miguel Asensio, P. (2007). El Derecho de los Negocios Internacionales. Primera Edición Madrid España p.p. 561 y s.s.

Galgano, F. \& Marrella, F. (2004). Diritto del Commercio Internazionale.Cedam, Padova, p. 17 y siguientes.

Galgano, F. (2005). La Globalización en el espejo del derecho. Santa Fe de Argentina, Editorial Rubinzal Culzoni.

Garro, A. (1992). Armonización y Unificación del Derecho Privado en América Latina. Centro de Estudio de Derecho Comparado y Extranjero. Roma. Disponible en: http:// www.crdcs.org/garro.html

Herber, R. (2003). Lex Mercatoria 'und Principles' - gefahrliche Irrilichter im internationalen Kraufrecht, Internationales Handelsrecht.

Lando, O. (2003 mayo). Some Features of the Law of Contract in the Third Millennium. P. 356. Disponible en: http://frontpage. cbs.dk/law commission_on_european contract_law/literature/lando1.doc

Legrand, P. (1997). Modern Law Review, Against a European Civil Code. p. 44.

Luppino, P. A. (2000). Revista Iberoamericana de Arbitraje Comercial. El Papel del 
Municipio en la Aldea Global y Resolución de Conflictos. Buenos Aires, Argentina.

Mereminskaya, E. A. (2003). Revista de Derecho Universidad Austral Vol. XV. Impactos de la Integración Económica en la Aplicación del Derecho Privado. Chile, 2003, p.p. 59-73.

Mereminskaya, E. \& Mascareno, A. A. (2005). Lexis - Nexis Tomo II, Sesquicentenario del Código Civil de Andrés Bello: pasado, presente y futuro de la codificación, Santiago de Chile, p.p. 1391 - 1427

Möllers, T. (2000). The American Journal of Comparative Law, The Role of Law in European Integration, p.688 y s.s

Oviedo Albán J. (2007) Regulación del contrato de compraventa internacional de mercaderías. Bogotá D.C.

Quintero Espinosa, L. A. (2004). Revista electrónica de difusión científica CIVILIZAR, Hacia un sistema contractual uniforme, Universidad Sergio Arboleda, Bogotá, Colombia. Disponible en: http://wwwusergio arboleda.edu.co/civilizar.

Rojo, Á. (1981). Crisis de la empresa y crisis de los procedimientos concursales. $\mathrm{P}$. 269293. RDCO. Año 14, Junio 1981 No. 80/81. Depalma, Argentina.

Rouillon, A. A. (2000 junio). ANALES de la Academia Nacional de Derecho y Ciencias Sociales, No. 38. Sesión pública, Concursos con Repercusión Transnacional. Buenos Aires, Argentina.

Sacco, R. (2001) Diversity and Uniformity in the Law, The American Journal of Comparative Law. Proyectos científicos dedicados al derecho comparado en Europa en internet: The Study Group on a European Civil Code (www.sgecc.net), The Common Core of European Private Law (www.jus.unitn.it/dsg/ common-core/home.html).
Schmidt, ZGR (1986). Fundamentos del nuevo derecho concursal Alemán, Estudios sobre el anteproyecto de Ley concursal de 2001. Tomado de García Villaverde, Ureba Alonso \& Pulgar, Madrid 2002 p. 22.

Sarmiento Sosa, C.J. A. (2006, Enero). Revista internauta Practica Jurídica No. 17, Algunas acotaciones sobre globalización y Unificación del derecho en Iberoamérica.

Rogowki, R. (2004) Aufbruch in das Weltrecht. Thesen zu Recht und Politik in Luhmanns Weltgesellschaft, Aufbruch in den rechtsfeien Roum: Nourmvirulenz als kulturelle Ressource, Heidelberg, Manutius Verlag. Disponible en: http://www.iablis. com/iablis_t/2004/rogowski.htm

Teubner, G. (1996) Soziale Systeme, No. 2. Des Konigs viele Leiber. Die Selbsdekonstruktion der Herarchie des Rechts, Disponible en http://www.soziale-systeme.ch/leseproben /teubner.htm

Teubner, G. (1996) "Globale Bukowina. Zur Emergenz eines transnationalen Rechtspluralismus", Basler Schiften zur europaischen Integration, No. 21 Europainstitut der Universitat Basel, 1996, Rogowski, Ralf, "Aufbruch in das Weltrecht. Thesen zu Recht und Politik in Luhmanns Weltgesellshaft".

Veiga Copo, A. (2004) Los Privilegios concursales. Segunda Edición. Granada, España. Ed. Comares

Veiga Copo, A. (2004 Julio). La delimitación de la masa pasiva en el concurso: del crédito privilegiado al subordinado. Trabajo sobre la reforma de la legislación concursal: Estudio sistemático de la Leyes 22 de 2003 y 8 de 2003. p. $109-170$.

Virgoós Soriano M, \& Garcimartín Alférez F.J. (2002) El Derecho concursal 
europeo: un ensayo sobre su racionalidad interna ", REDC, No., 1.

Zambrana Moral, P. (2001). Derecho Concursal Histórico. Trabajos de Investigación. Facultad de Derecho Universidad de Málaga.

Zimmermann, R. \& Whittaker, S. (2000). The Common Core of European Private Law Project: Good faith in European Contract Law. Cambridge, University.

\section{Normatividad Citada}

Convenio de Estambul Junio 5 de 1990.

Convenio de 23 de Noviembre de 1995, sobre aspectos internacionales de los procedimientos de insolvencia.

Convenio de Bruselas Septiembre 27 de 1968 sobre procedimiento concursal.

Ley Modelo de la UNCITRAL 2003, sobre Insolvencia Transfronteriza y su guía para la incorporación por parte de los Estados.

Ley 1116 de 2006. Nuevo Régimen Colombiano de Insolvencia Empresarial.

Reglamento (C.E. ) Número 1346 del 29 de Mayo de 2000, sobre Procedimientos de Insolvencia. 
